\title{
Utility of Transcutaneous Bilirubinometer in Tertiary Care Hospital
}

\author{
Kumar V' , Kahlon $\mathrm{PS}^{2}$, Singh $\mathrm{P}^{3}$, Singh $\mathrm{K}^{4}$, Sharma $\mathrm{A}^{5}$
}

\begin{abstract}
Introduction: Hyperbilirubinemia is one of the most vexing problems that may occur in $60 \%$ of term and $80 \%$ of preterm neonates. In order to reduce the risk of developing serious hyperbilirubinemia, it is vital to identify jaundiced infants who are in need of treatment as soon as possible. The objectives of this study were to find whether transcutaneous bilirubin (TcB) measurement correlates with total serum bilirubin (TSB) levels, measured with standard laboratory method and to analyse the effect of gestational age, birth weight and postnatal life on TCB and TSB. Material and Methods: A prospective study was conducted in the Department of Paediatrics, Government Medical College, Amritsar on 300 neonates with visible jaundice. These neonates were divided into various groups depending upon gestational age, birth weight and day of life. TCB readings were recorded at forehead and sternum and serum bilirubin level was measured within 30 minutes. Test of significance applied was unpaired T-test; mean value, $p$-value, standard deviation and Pearson's correlation coefficient ' $r$ ' were calculated. Results: Overall Mean value TcB at forehead was 15.32 with $\mathrm{SD} \pm 2.75$, mean $\mathrm{TCB}$ at sternum was 14.94 with SD \pm 2.51 , mean value of TSB was 13.80 with $S D \pm 2.15$. Pearson's correlation coefficient $r$ was 0.895 for TcB forehead vs TSB, 0.903 for TcB sternum vs TSB and 0.966 between TcB forehead vs TcB sternum. Conclusion: TcB levels correlates well with the gold standard measurement of TSB. Gestational age, birth weight and day of life had no effect on TcB and TSB correlation. Transcutaneous bilirubinometer can thus be used to measure bilirubin level as a screening method for neonatal hyperbilirubinemia.
\end{abstract}

Key words: Hyperbilirubinemia, Transcutaneous bilirubinometer, Serum bilirubin
${ }^{1}$ Dr. Vijay Kumar, MBBS, MD, ${ }^{2}$ Dr. Pardeep Singh Kahlon, MBBS, DCH, MD, Assistant Professor, ${ }^{3} \mathrm{Dr}$. Palwinder Singh, MBBS, MD, Professor, ${ }^{4} \mathrm{Dr}$. Karnail Singh, MBBS, MD, Professor, ${ }^{5} \mathrm{Dr}$. Anubha Sharma, MBBS, MD, Senior Resident. All from the Department of Paediatrics, Government Medical College, Amritsar, Punjab, India.

\section{Address for correspondence}

Dr. Pardeep Singh Kahlon

Department of Paediatrics Government Medical College, Amritsar, Punjab

E-mail: docpsk@yahoo.com

Acknowledgements: None

Funding: Nil

Conflict of Interest: None

Permission from IRB: Yes

\section{How to cite}

Kumar V, Kahlon PS, Singh P, Singh K, Sharma A. Utility of Transcutaneous Bilirubinometer in Tertiary Care Hospital. J Nepal Paediatr Soc 2017;37(1):72-78.

doi:http://dx.doi.org/10.3126/jnps.v37i1.17117

\section{Introduction}

$\mathrm{H}^{\prime}$ yperbilirubinemia is one of the most vexing problems that may occur in $60 \%$ of term and $80 \%$ of preterm neonates. Most neonates develop hyperbilirubinemia during the first week of their life $e^{1,2}$.

Major risk factors for development of severe hyperbilirubinemia
This work is licensed under a Creative Commons Attribution 3.0 License.

\section{(c) (i)}


in neonates include pre-discharge TSB or TcB level in the high-risk zone, jaundice observed in the first 24 hours, blood group incompatibility ( $\mathrm{Rh} / \mathrm{ABO})$, late preterm(35-36 weeks gestational age), h/o previous sibling having received phototherapy, cephalhaematoma or significant bruising, glucose-6-phosphatase dehydrogenase (G6PD) deficiency and other hereditary haemolytic anaemias, exclusive breast feeding particularly if nursing is not going well and weight loss is excessive. Minor risk factors arepre-discharge TSB or TcBlevel in the intermediate-risk zone, previous sibling with jaundice, macrosomic infants of diabetic mother and gestational age 37-38 weeks ${ }^{3}$.

Hyperbilirubinemia may be entirely physiological or present as the first sign of serious illness i.e. Kernicterus which is a devastating but a rare disease with an incidence ranging from 0.4 to $2.9 / 100000$ live births $s^{4,5,6,7,8}$. Bilirubin encephalopathy in term and preterm new-born is preventable. Neonatal jaundice is caused by bilirubin deposition in the skin, as a result of increased red cell breakdown and decreased bilirubin excretion ${ }^{9}$. In order to reduce the risk of developing serious hyperbilirubinemia, it is vital to identify jaundiced infants who are in need of treatment as soon as possible ${ }^{10}$.

Visual assessment of diagnosis of neonatal hyperbilirubinemia is not ideal. TSB level assessment in clinical laboratory is an objective method, but the results provided are not real-time and there are inter-lab and intra-lab variations. To overcome these drawbacks, noninvasive methods of bilirubin measurements have been proposed. Transcutaneous measurement of bilirubin concentration is considered to be ideal for neonatal jaundice screening ${ }^{11.12}$. Transcutaneous bilirubinometer measures the intensity of yellow colour in the skin and subcutaneous tissue and correlates it with the serum bilirubin concentration in new-born infants ${ }^{13}$. It is reported to be safe, simple, objective, reproducible, cost effective, non-invasive modality in the screening and monitoring of jaundiced new-born infants. A significant correlation has been found between serum bilirubin and transcutaneous bilirubin levels which is affected by gestational age, use of phototherapy, birth weight, color of skin, degree of jaundice and race ${ }^{14-20}$. Reduction in the number of invasive blood tests is associated with reduction in pain and discomfort for new-borns, parental distress and reduction in health costs. American Academy of Pediatrics (AAP) considers the use of transcutaneous bilirubin measurement in monitoring jaundice in new born infants, and studies have confirmed the importance of the same ${ }^{3,16,18}$.

The present study was conducted to find whether transcutaneous bilirubin (TcB) measurement correlates with total serum bilirubin (TSB) levels, measured with standard laboratory method and to analyse the effect of gestational age, birth weight and postnatal life on TcB and TSB.

\section{Materials and Methods}

This prospective hospital based study was carried out in the Department of Paediatrics, Government Medical College, Amritsar. The study sample consisted of 300 neonates born in Department of Gynaecology and Obstetrics and/or admitted in Department of Paediatrics, Government Medical College, Amritsar. All neonates who presented with jaundice or developed visible jaundice during hospital stay (stay of new-born or mother) and for whom decision for obtaining lab value of serum bilirubin was made, were enrolled in the study after obtaining written consent from the caregivers. These neonates were divided into different groups depending upon gestational age, mode of delivery, birth weight and day of life.

Transcutaneous bilirubin (TcB) measurements were taken using a Transcutaneous bilirubinometer (Bilitest-2000) over the mid- sternum area and forehead. Transcutaneous bilirubinometer work by directing light into the skin of the neonate and measuring the intensity of specific wavelength that is returned. The meter analyzes the spectrum of optical signal reflected from the neonate's subcutaneous tissues. These optical signals are converted to electrical signal by a photocell and are analyzed by a microprocessor to generate a serum bilirubin value.

The optic head of the meter is gently pressed against the neonate's skin (usually forehead or upper part of sternum). For correct measurement, the optic head should make full contact with the skin and there should be no gaps between the head and the skin. This should be achieved by gentle pressure. The procedure lasted for 2-3 seconds and was accompanied by a soft sound. The commonly used sites are the forehead and the upper end of sternum. The correlation coefficients for other sites such as the lower limbs are poor. For each site three values were recorded at a time and the median value of all the three was noted. The result was shown in $\mathrm{mg} / \mathrm{dl}$. Serum bilirubin level was obtained within 30 minutes of transcutaneous bilirubin (TcB) measurements using standard laboratory (diazo) method.

\section{Results}

A total of 300 newborns were included in the study, out of which $174(58 \%)$ were male and $126(42 \%)$ were females. After statistical analysis, results obtained were: mean value TcB at forehead was 15.32 with S.D. \pm 2.75 , 
mean TcB at sternum was 14.94 with S.D. \pm 2.51 , and mean value of TSB was 13.80 with S.D. \pm 2.15 . (Table 1).

The study population was divided into three groups based on gestational age, preterm $\leq 34$ weeks gestation (64 neonates), late preterm 35-37 weeks gestation (133 neonates) and term $>37$ weeks (103 neonates). Mean TcB in the three groups at forehead was 11.55 with SD $\pm 1.71,15.23$ with $\mathrm{SD} \pm 1.73$ and 17.77 with $\mathrm{SD} \pm 1.22$ respectively. Mean TcB at sternum was 11.54 with $S D$ $\pm 1.63,14.88$ with $\mathrm{SD} \pm 1.64$ and 17.11 with $\mathrm{SD} \pm 1.16$ respectively. Mean value of the TSB was 10.94 with SD $\pm 1.65,13.96$ with $S D \pm 1.51$ and 15.37 with $S D \pm 1.13$ respectively in the three groups. Table and figure 2 show the correlation between TcB and TSB.

The study population was divided into three groups according to weight. In the first group there were 34 neonates having weight $<1.5 \mathrm{~kg}$. Mean value of TcB at forehead was 11.30 with SD \pm 1.91 , mean value of TcB at sternum was 11.21 with $S D \pm 1.72$, and mean value of TSB was 10.64 with SD \pm 1.76 .

In the second group there were 146 neonates weighing between 1.51 to $2.5 \mathrm{Kg}$. Mean value of TcB at forehead was 14.50 with SD \pm 2.17 , mean value of TcB at sternum was 14.25 with $S D \pm 2.02$ and mean value of TSB was 13.41 with $S D \pm 1.86$.

In the third group there were 120 neonates weighing $>2.5 \mathrm{~kg}$. Mean value of $\mathrm{TcB}$ at forehead was 17.46 with $S D \pm 1.50$. Mean value of TcB at sternum was 16.83 with $S D \pm 1.37$ and mean of TSB was 15.18 with SD \pm 1.28 . Table and figure 3 show the detailed correlation.
The study population was divided into groups based on day of life at presentation. Out of 300 neonates, 10 presented on day two of life, Mean value of TcB at forehead was 14.71 with SD \pm 2.9 , mean value of $T c B$ at sternum was 14.14 with $S D \pm 2.97$, mean value of TSB was 13.37 with SD \pm 3.15 .

Total of 61 neonates presented on day three of life, mean TcB at forehead was 14.86 with $S D \pm 3.15$, mean value of $T c B$ at sternum was 14.51 with $S D \pm 2.90$, mean value of TSB was 13.24 with $S D \pm 2.57$.

Similarly 80 neonates on the fourth day of life, mean TcB at forehead was 15.43 with SD \pm 2.66 , mean $\mathrm{TcB}$ at sternum was 15.07 with $\mathrm{SD} \pm 2.45$, mean value of TSB was 13.97 with SD \pm 2.00 .

Altogether 67 neonates presented on the fifth day of life. Mean value of TcB at forehead was 15.72 with $\mathrm{SD} \pm 2.68$, mean value of TcB at sternum was 15.21 with $\mathrm{SD} \pm 2.41$, mean value of TSB was 14.09 with $S D \pm 2.03$.

Likewise 44 neonates presented on day 6 of life mean value of TcB at forehead was 15.09 with SD \pm 2.77 , mean TcB at sternum was 14.85 with $\mathrm{SD} \pm 2.52$, mean value of TSB was 13.60 with $S D \pm 2.02$.

38 neonates presented on day $7^{\text {th }}$ of life. Mean value of $\mathrm{TcB}$ at forehead was 15.52 with $\mathrm{SD} \pm 2.27$, mean value of $T c B$ at sternum was 15.13 with $S D \pm 1.95$, mean value of TSB was 14.16 with $S D \pm 1.9$. The results for the same as well as their correlation at different sites are depicted in Table-4/Figure-2.

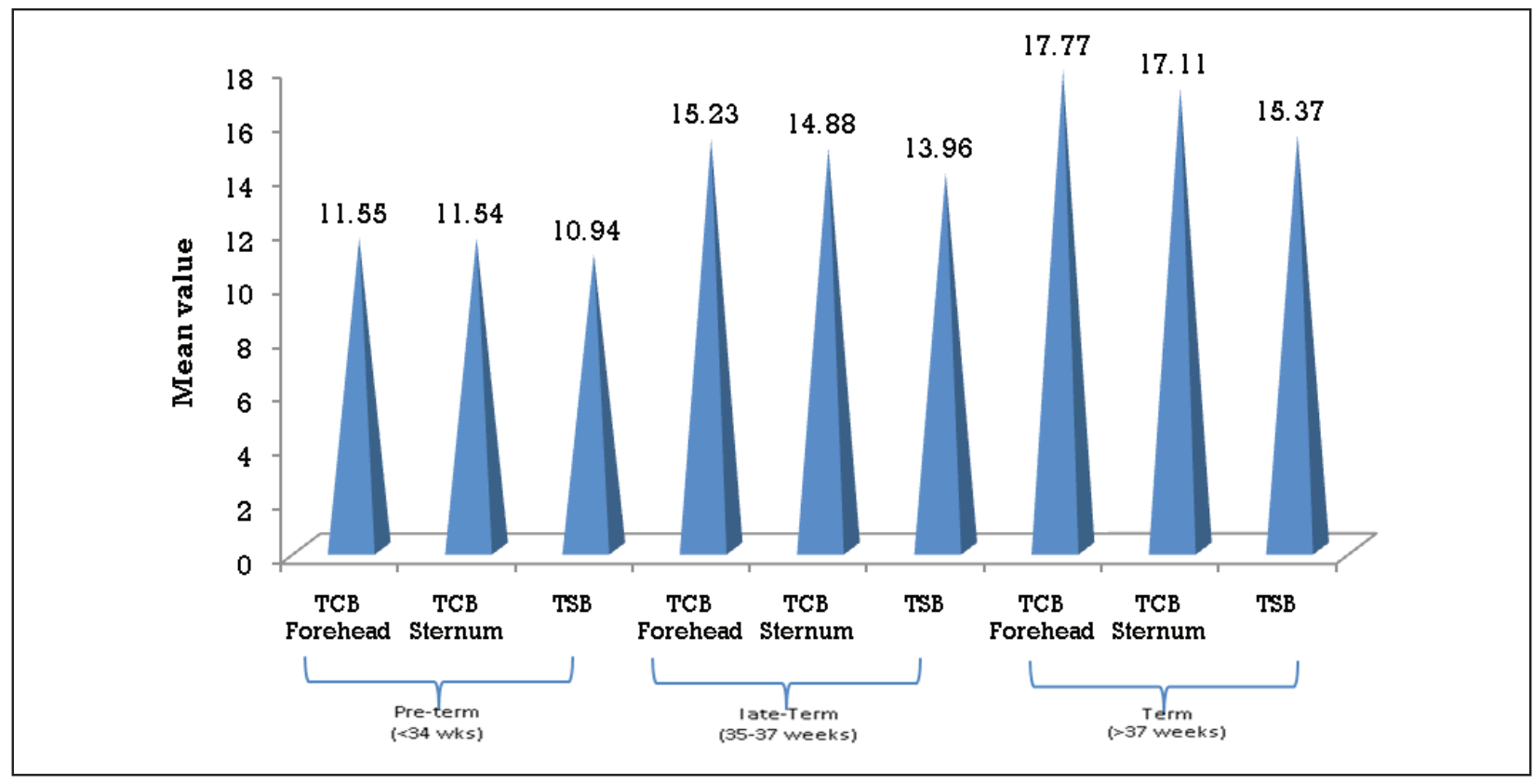

Fig 1: Showing Gestation wise Correlation between Tcb and TSB 


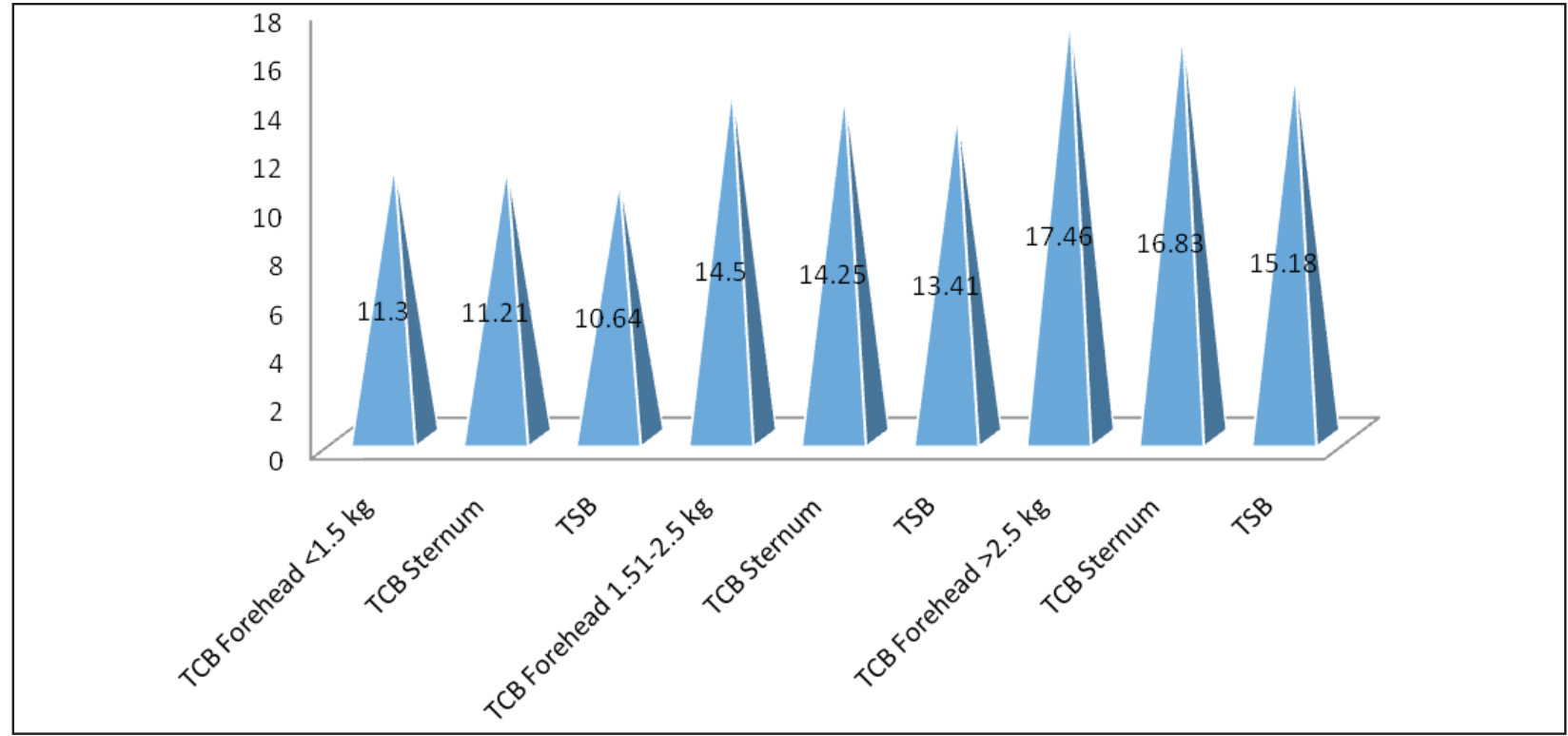

Fig 2: Showing Mean TcB Forehead, TcB Sternum and TCS according to Birthweight

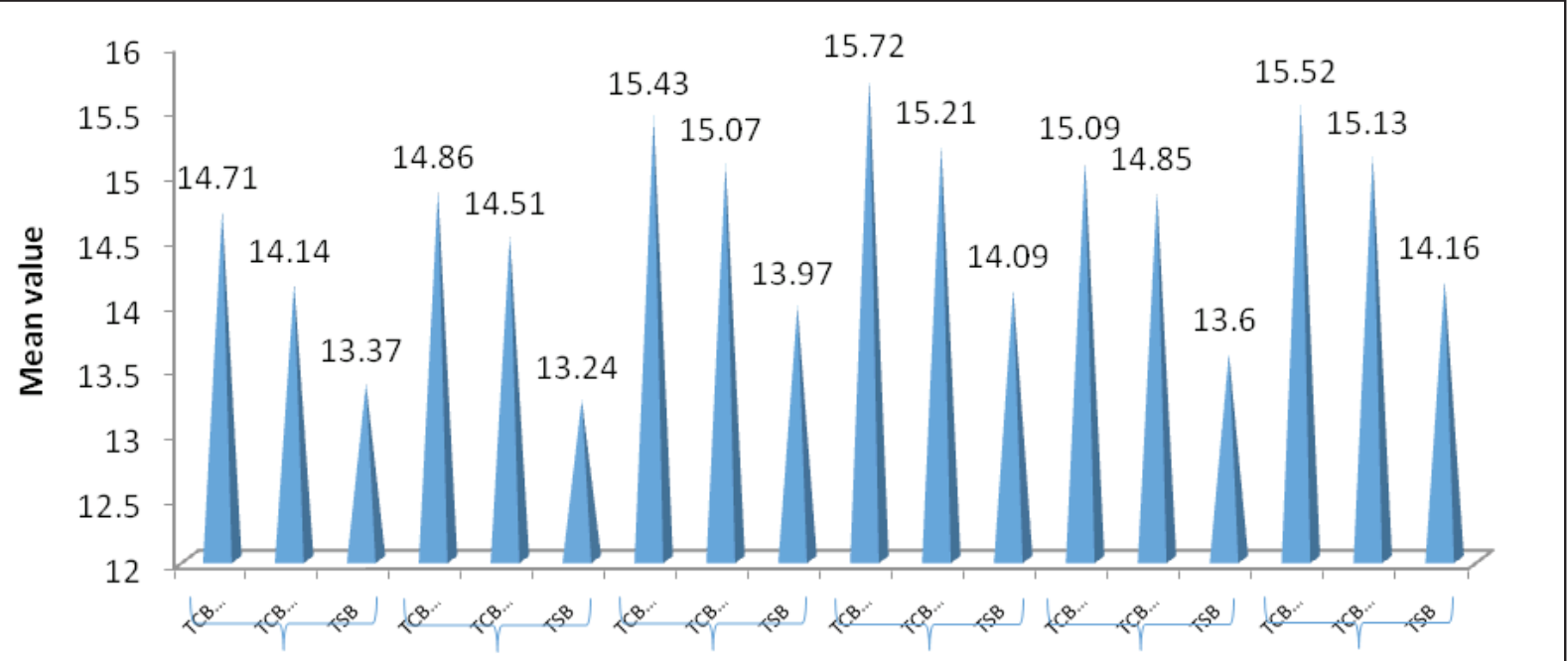

Fig 3: Showing day of Life wise Correlation between Tcb and TSB

Table 1: Showing overall correlation between TcB forehead, TcB sternum and TSB

\begin{tabular}{lccccccc}
\hline & N & Mean \pm SD & Comparison & $\begin{array}{c}\text { Difference } \\
\text { Mean } \pm \text { SE }\end{array}$ & $\begin{array}{c}\text { 't'- } \\
\text { value }\end{array}$ & $\boldsymbol{p}$-value & $\boldsymbol{r}$-value \\
\hline TcB Forehead & 300 & $15.32 \pm 2.75$ & TcB Forehead vs TSB & $1.52 \pm 0.73$ & 20.74 & $<0.001^{* *}$ & 0.895 \\
\hline TcB Sternum & 300 & $14.94 \pm 2.51$ & TcB Sternum vs TSB & $1.13 \pm 0.06$ & 18.11 & $<0.001^{* *}$ & 0.903 \\
\hline TSB & 300 & $13.80 \pm 2.15$ & TcB Forehead vs TcBSternum & $0.38 \pm 0.04$ & 9.19 & $<0.001^{* *}$ & 0.966 \\
\hline
\end{tabular}

SD: Standard deviation; SE Standard error of mean; ${ }^{* *} p<0.001$; Highly significant 
Table 2: Showing Gestation wise Correlation between TcB andTSB

\begin{tabular}{|c|c|c|c|c|c|c|c|c|}
\hline $\begin{array}{l}\text { GESTATIONAL } \\
\text { AGE IN WEEKS }\end{array}$ & & $\mathbf{N}$ & Mean \pm SD & Comparison & $\begin{array}{l}\text { Difference } \\
\text { Mean } \pm \text { SE }\end{array}$ & $\begin{array}{c}\text { 't'- } \\
\text { value }\end{array}$ & $p$-valve & $r$-value \\
\hline \multirow{3}{*}{$\begin{array}{l}\text { Preterm } \\
\text { (34 weeks) }\end{array}$} & TcBForehead & 64 & $11.55 \pm 1.71$ & TcB Forehead vs TSB & $0.60 \pm 0.05$ & 11.07 & 0.000 & 0.968 \\
\hline & TcBSternum & 64 & $11.54 \pm 1.63$ & TcB Sternum vs TSB & $0.60 \pm 0.05$ & 10.13 & 0.000 & 0.959 \\
\hline & TSB & 64 & $10.94 \pm 1.65$ & $\begin{array}{l}\text { TcB forehead vs } \\
\text { Sternum }\end{array}$ & $0.00 \pm 0.07$ & 0.02 & 0.000 & 0.945 \\
\hline \multirow{3}{*}{$\begin{array}{l}\text { Late-PreTerm } \\
(35-37 \text { weeks) }\end{array}$} & TcBForehead & 133 & $15.23 \pm 1.73$ & TcB Forehead vs TSB & $1.27 \pm 0.07$ & 16.62 & 0.000 & 0.860 \\
\hline & TCB Sternum & 133 & $14.88 \pm 1.64$ & TcB Sternum vs TSB & $0.91 \pm 0.05$ & 15.83 & 0.000 & 0.913 \\
\hline & TSB & 133 & $13.96 \pm 1.51$ & $\begin{array}{l}\text { TcB forehead vs } \\
\text { Sternum }\end{array}$ & $0.35 \pm 0.06$ & 05.63 & 0.000 & 0.909 \\
\hline \multirow{3}{*}{$\begin{array}{l}\text { Term } \\
\text { (>37 weeks) }\end{array}$} & TcBForehead & 103 & $17.77 \pm 1.22$ & TcB Forehead vs TSB & $2.40 \pm 0.14$ & 16.48 & 0.027 & 0.218 \\
\hline & TcBSternum & 103 & $17.11 \pm 1.16$ & TcB Sternum vs TSB & $1.74 \pm 0.14$ & 12.15 & 0.045 & 0.198 \\
\hline & TSB & 103 & $15.37 \pm 1.13$ & $\begin{array}{l}\text { TcB forehead vs } \\
\text { Sternum }\end{array}$ & $0.66 \pm 0.06$ & 09.56 & 0.000 & 0.828 \\
\hline
\end{tabular}

SD: Standard deviation; SE Standard error of mean; $p<0.005$; significant

Table 3: Showing Weight wise Correlation between Tcb and TSB

\begin{tabular}{|c|c|c|c|c|c|c|c|c|}
\hline Weight in $\mathrm{Kg}$ & & $\mathbf{N}$ & Mean \pm SD & Comparison & $\begin{array}{l}\text { Difference } \\
\text { Mean } \pm \text { SE }\end{array}$ & $\begin{array}{c}\text { ' } t \text { ' } \\
\text { value }\end{array}$ & $p$-value & $r$-value \\
\hline \multirow{3}{*}{$<=1.5 \mathrm{~kg}$} & TcB Forehead & 34 & $11.30 \pm 1.91$ & TcB forehead vs TSB & $0.66 \pm 0.07$ & 9.135 & $<0.001^{* *}$ & 0.977 \\
\hline & TcB Sternum & 34 & $11.21 \pm 1.72$ & TcB Sternum vs TSB & $0.57 \pm 0.08$ & 7.127 & $<0.001^{* *}$ & 0.964 \\
\hline & TSB & 34 & $10.64 \pm 1.76$ & $\begin{array}{l}\text { TcB forehead vs } \\
\text { Sternum }\end{array}$ & $0.08 \pm 0.10$ & 0.822 & $>0.001$ & 0.950 \\
\hline \multirow{3}{*}{$1.51-2.5 \mathrm{~kg}$} & TcB Forehead & 146 & $14.50 \pm 2.17$ & TcB Forehead vs TSB & $1.09 \pm 0.07$ & 14.817 & $<0.001^{* *}$ & 0.914 \\
\hline & TcB Sternum & 146 & $14.25 \pm 2.02$ & TcB Sternum vs TSB & $0.83 \pm 0.06$ & 14.548 & $<0.001^{* *}$ & 0.940 \\
\hline & TSB & 146 & $13.41 \pm 1.86$ & $\begin{array}{l}\text { TcB forehead vs } \\
\text { Sternum }\end{array}$ & $0.26 \pm 0.06$ & 4.212 & $<0.001^{* *}$ & 0.940 \\
\hline \multirow{3}{*}{$>2.5 \mathrm{~kg}$} & TcB Forehead & 120 & $17.46 \pm 1.50$ & TcB forehead vs TSB & $2.28 \pm 0.13$ & 17.666 & $<0.001^{* *}$ & 0.490 \\
\hline & TcBSternum & 120 & $16.83 \pm 1.37$ & TcB Sternum vs TSB & $1.66 \pm 0.12$ & 13.437 & $<0.001^{* *}$ & 0.479 \\
\hline & TSB & 120 & $15.18 \pm 1.28$ & $\begin{array}{l}\text { TcB forehead vs } \\
\text { Sternum }\end{array}$ & $0.62 \pm 0.06$ & 10.218 & $<0.001^{* *}$ & 0.895 \\
\hline
\end{tabular}

SD: Standard deviation; SE Standard error of mean; NS: $p>0.05$; Not significant; ${ }^{* *} p<0.001$; highly significant

Table 4: Showing day of Life wise Correlation between Tcb and TSB

\begin{tabular}{|c|c|c|c|c|c|c|c|c|}
\hline $\begin{array}{l}\text { Day of } \\
\text { life }\end{array}$ & & $\mathbf{N}$ & Mean \pm SD & Comparison & $\begin{array}{l}\text { Difference } \\
\text { Mean } \pm \text { SE }\end{array}$ & 't'-value & $p$-value & $r$-value \\
\hline \multirow{3}{*}{ Day 2} & TcB Forehead & 10 & $14.71 \pm 2.91$ & TcB Forehead vs TSB & $1.34 \pm 0.52$ & 02.53 & 0.002 & 0.851 \\
\hline & TcB Sternum & 10 & $14.14 \pm 2.97$ & TcB Sternum vs TSB & $0.77 \pm 0.29$ & 02.64 & 0.000 & 0.957 \\
\hline & TSB & 10 & $13.37 \pm 3.15$ & $\begin{array}{l}\text { TcB Forehead vs } \\
\text { Sternum }\end{array}$ & $0.57 \pm 0.35$ & 01.61 & 0.000 & 0.929 \\
\hline \multirow{3}{*}{ Day 3} & TcB Forehead & 61 & $14.86 \pm 3.15$ & TcB Forehead vs TSB & $1.61 \pm 0.23$ & 06.91 & 0.000 & 0.816 \\
\hline & TCB Sternum & 61 & $14.51 \pm 2.90$ & TcB Sternum vs TSB & $1.27 \pm 0.21$ & 05.92 & 0.000 & 0.820 \\
\hline & TSB & 61 & $13.24+2.57$ & $\begin{array}{l}\text { TcB Forehead vs } \\
\text { Sternum }\end{array}$ & $0.34 \pm 0.09$ & 03.46 & 0.000 & 0.971 \\
\hline \multirow{3}{*}{ Day 4} & TcB Forehead & 80 & $15.43 \pm 2.66$ & TcB Forehead vs TSB & $1.46 \pm 0.12$ & 11.78 & 0.000 & 0.962 \\
\hline & TcB Sternum & 80 & $15.07 \pm 2.45$ & TcB Sternum vs TSB & $1.10 \pm 0.10$ & 10.56 & 0.000 & 0.932 \\
\hline & TSB & 80 & $13.97 \pm 2.00$ & $\begin{array}{l}\text { TcB Forehead vs } \\
\text { Sternum }\end{array}$ & $0.36 \pm 0.07$ & 05.19 & 0.000 & 0.974 \\
\hline
\end{tabular}


Table 4 cont ...

\begin{tabular}{|c|c|c|c|c|c|c|c|c|}
\hline $\begin{array}{l}\text { Day of } \\
\text { life }\end{array}$ & & $\mathbf{N}$ & Mean \pm SD & Comparison & $\begin{array}{l}\text { Difference } \\
\text { Mean } \pm \text { SE }\end{array}$ & 't'-value & $p$-value & $r$-value \\
\hline \multirow{3}{*}{ Day 5} & TcB Forehead & 67 & $15.72 \pm 2.68$ & TcB Forehead vs TSB & $1.63 \pm 0.13$ & 12.39 & 0.000 & 0.932 \\
\hline & TcB Sternum & 67 & $15.21 \pm 2.41$ & TcB Sternum vs TSB & $1.11 \pm 0.10$ & 10.46 & 0.000 & 0.937 \\
\hline & TSB & 67 & $14.09 \pm 2.03$ & $\begin{array}{l}\text { TcB Forehead vs } \\
\text { Sternum }\end{array}$ & $0.51 \pm 0.09$ & 05.35 & 0.000 & 0.958 \\
\hline \multirow{3}{*}{ Day 6} & TcB Forehead & 44 & $15.09 \pm 2.77$ & TcB Forehead vs TSB & $1.49 \pm 0.15$ & 09.68 & 0.000 & 0.958 \\
\hline & TcB Sternum & 44 & $14.85 \pm 2.52$ & TcB Sternum vs TSB & $1.25 \pm 0.13$ & 09.43 & 0.000 & 0.948 \\
\hline & TSB & 44 & $13.60 \pm 2.02$ & $\begin{array}{l}\text { TcB Forehead vs } \\
\text { Sternum }\end{array}$ & $0.23 \pm 0.10$ & 02.22 & 0.000 & 0.969 \\
\hline \multirow[t]{3}{*}{ Day 7} & TcB Forehead & 38 & $15.52 \pm 2.27$ & TcB Forehead vs TSB & $1.35 \pm 0.15$ & 08.69 & 0.000 & 0.937 \\
\hline & TcB Sternum & 38 & $15.13 \pm 1.95$ & TcB Sternum vs TSB & $0.96 \pm 0.11$ & 08.40 & 0.000 & 0.939 \\
\hline & TSB & 38 & $14.16 \pm 1.59$ & $\begin{array}{l}\text { TcB Forehead vs } \\
\text { Sternum }\end{array}$ & $0.38 \pm 0.09$ & 03.90 & 0.000 & 0.970 \\
\hline
\end{tabular}

SD: Standard deviation; SE: Standard error of mean; $p<0.001$; Highly significant

\section{Discussion}

As early discharge from the hospital is becoming more frequent, there has been increasing concern that infants may develop serious sequel of unrecognized hyperbilirubinemia. This concern has led to a number of recommendations for universal screening for neonatal hyperbilirubinemia, and ultimately resulted in the publication of the 2004 American Academy of Pediatrics guidelines for management of neonatal hyperbilirubinemia. ${ }^{3}$

Our study investigated the correlation of TcB levels with TSB levels in the study population with the intent of using Transcutaneous bilirubinometer as a screening tool for clinically significant neonatal hyperbilirubinemia. According to our study, TcB levels correlated well with the gold standard measurement of TSB. The Pearson's correlation coefficient ' $r$ ' was 0.895 between TcB forehead vs TSB, 0.903 between TcB sternum vs TSB and 0.966 between TcB forehead vs TcB sternum. In preterm neonates Pearson's correlation coefficient' ' $r$ ' was 0.968 for TcB forehead vs TSB, 0.959 for TcB sternum vs TSB and 0.945 between TcB forehead vs sternum.

Our study was in agreement with following studies conducted earlier. Yamauchi et. $\mathrm{al}^{22}$. conducted a study on 130 neonates found out that transcutaneous bilirubin levels showed a highly significant correlation ( $r=0.99$ ) with total serum bilirubin concentration. In a similar study conducted by Gaganet. $\mathrm{al}^{23}$. correlation coefficients of
0.900 at forehead and 0.908 at sternum were noted. In another study conducted by Mansouri et. al. ${ }^{24}$ on 200 term neonates to compare Transcutaneous bilirubin and total serum bilirubin a good correlation $(r=0.89)$ was observed between TcB and TSB. These findings are similar to our study.

Gestational age wise also, we found that significant correlation was present between TcB and TSB. In a similar study conducted by Stillova et. al. ${ }^{21}$ to evaluate the accuracy of transcutaneous bilirubinometry in preterm new-borns less than 32 weeks of gestation, correlation coefficient $(r=0.933)$ was observed between total serum bilirubin and transcutaneous bilirubin values measured over sternum. These findings were in agreement with our study.

Birth weight wise we found that good correlation was present between TCB and TSB. Our findings were in agreement with study conducted by Stillova et. al. ${ }^{34}$ on VLBW infants, the correlation coefficients for TSB versus TcB obtained over forehead and sternum were $0.915,0.862$ respectively.

\section{Conclusion}

From this study it is concluded that transcutaneous bilirubinometer can be used to measure bilirubin level as a screening method for neonatal hyperbilirubinemia. TcB is a non-invasive, non-traumatic experience for the neonate as well as parents. Moreover it gives quick results, avoids repeated blood sampling, is cost effective and does not need highly trained personnel. 


\section{References}

1. Kleigman RM, Stanton BF, St Geme JW, Schor NF, Behrman RE. Jaundice and Hyperbilirubinemia in newborn, Nelson Textbook of Pediatrics $19^{\text {th }} \mathrm{Ed}$. Saunders; 2012:603-607

2. Szabo P, Wolf M, Bucher HU, Haensse D, Fauchere JC, Arlettaz R. Assessment of jaundice in preterm neonates: comparison between clinical assessment, two transcutaneous bilirubinometers and serum bilirubin values. ActaPaediatr2004;93:1491-495. doi:10.1080/08035250410018328.

3. AAP Subcommittee on Hyperbilirubinemia. Management of hyperbilirubinemia in the newborn infant 35 or more weeks of gestation. Pediatrics 2004;114(1):297-316.

4. Singh M. Jaundice, Care of the Newborn, 7th Edition, New Delhi, Sagar publication; 2010:254-70.

5. Ebbesen F, Andersson C, Verder H. Extreme hyperbilirubinemia in term and near-term infants in Denmark. ActaPaediatr2005;94(1):59-64.

6. Ebbesen F. Recurrence of kernicterus in term and near-term infants in Denmark. ActaPaediatr2000;89(10):1213-217.

7. Bjerre JV, Petersen JR, Ebbesen F. Surveillance of extreme hyperbilirubinemia in Denmark: A method to identify the newborn infants. ActaPaediatr2008;97(8):1030-34.doi:10.1111 /j.1651-2227.2008.00879.

8. Burke BL, Robbins JM, Bird TM, Hobbs CA Nesmith C, Tilford JM. Trends in hospitalizations for neonatal jaundice and kernicterus in United States. Pediatrics2009;123(2):524-32.doi:10.1542/peds.20072915

9. Skae MS, Moise J, Clarke P. Is current management of neonatal jaundice evidence based? Arch Dis Child Fetal Neonatal Ed 2005;90:540.doi:10.1136/ adc.2004.070060.

10. Diamond I, Odell GB, Johnson L, Boggs TR, Lucey JF. Kernicterus: revised concepts of pathogenesis and management. Pediatrics 1966;38(4):539-46.

11. Bhutani VK, Johnson L, Sivieri EM. Predictive ability of a predischarge hour-specific serum bilirubin for subsequent significant hyperbilirubinemia in healthy-term and near-term newborns, Pediatrics 1999;103(1):6-14.
12. Bhutani VK, Johnson LH. Jaundice technologies: prediction of hyperbilirubinemiain term and near-term newborns. J Perinatol 2001;21(suppl 1):S76-S87.

13. Schumacher RD, Thornbery JM, Gutcher GR. Transcutaneous bilirubinometry a comparison of old and new methods. Pediatrics 1985;76:10-4

14. Yamanouchi I, Yamauchi I, Igarash I, Transcutaneous bilirubinometry: preliminary studies of non-invasive transcutaneous bilirubinometer in Okayama National Hospital. Pediatrics 1980;65:195-202.

15. Tan KL. Transcutaneous bilirubinometry in full term Chinese and Malay infants. ActaPaediatrScand1982;71:593-96.

16. Maisels MJ. Historical perspectives: transcutaneous bilirubinometry. Neo Reviews Org 2006;7(5):e217-e25.

17. Narang A, Buche VB. Evaluation of Minolta Jaundicemeter as a screening device in India. Indian Pediatr 1983;20:583-85.

18. Ip S, Chung M, Kulig J. American Academy of PediatricsSubcommittee on Hyperbilirubinemia. An evidence-based review on important issues concerning neonatal hyperbilirubinemia. Pediatrics2004;114(1):e130-e53.

19. Harish R, Sharma DB. Transcutaneous bilirubinometry in neonates: evaluation of Minolta AirshieldsJaundicemeter. Indian Pediatr 1998;35:26467.

20. Aroor AR, Christo GG, Kamath S, Venkatesh. Transcutaneous bilirubinometry in newborns. Indian Pediatr 1988;25:1073-77.

21. Stillova L, Matasova M, Zibolen M, Stilla J, Kolarovszka $\mathrm{H}$. Transcutaneous Bilirubinometry in Preterm Neonates. Indian Pediatrics 2009;46:405-8.

22. Yamauchi Y, Yamanouchi I. Comparison of Transcutaneous bilirubinometers. Biol Neonate 1989;56(5):257-62.

23. Mahajan G, Kaushal RK, Naveen S, Sharma RL and Monica N. Transcutaneous Bilirubinometer in Assessment of Neonatal Jaundice in Northern India. Indian Pediatr 2005;42:41-5.

24. Mansouri M, Mahmoodnejad A, Sarvestani R TandGharibi F. Comparison between transcutaneous and total serum bilirubin measurements in term neonates.Int J Pediatr2015;3(1):633-44.doi: 10.22083/ IJP.2015.4352. 